\title{
A Geology of Media and a New Materialism
}

Jussi Parikka in Conversation with Annika Richterich

\author{
"The design culture of the new \\ hides the archaic materials of the planet." \\ (PARIKKA 2015: 137)
}

Jussi Parikka's research focuses on interrelations between technological culture, ecology and media aesthetics. He has published widely on media archaeology and material media cultures. In 2015, he published A Geology of Media which explores media studies as study of material (metallic, mineral, chemical) components. Bridging between the natural sciences, arts and environmental ethics, the media theorist explores analytic approaches which show how natural resources enable media and how media impact the earth's ecosystem. His latest publication highlights the relevance and agency of the nonorganic as element in contemporary art, media studies and humanities. At the same time, it initiates a debate on the geophysical affordances of digital media. The email conversation with Jussi addresses core concepts and approaches suggested in A Geology of Media, and their implications for media studies and the humanities.

Annika Richterich (AR): In your latest book, you introduce a 'geology of media' as a temporal and spatial materialism of media culture. While you describe German media theory and particularly the work by Friedrich Kittler as one important type of media materialism, you criticise that it does not go 'far enough' since it is focused on technological products such as circuits and hardware. You propose that A Geology of Media goes beyond earlier notions of materialism. With regards to a media materialism as represented by Kittler, you raise the question: "from where do our notions of materiality stem and what is their ground?" (Parikka 2015: 3). When applying this to your own theory, which understanding of materiality is decisive for your 'geology of media' and a new media materialism?

Jussi Parikka (JP): I have worked on the notion of "new materialism" for some years now; with Dr Milla Tiainen, we organised the first of the New Materialism conferences in 2010 in Cambridge at Anglia Ruskin University. ${ }^{1}$ We were inter-

1 cf. http://ww2.anglia.ac.uk/ruskin/en/home/microsites/code/code_events/code_ events_archive/new_materials_symposium.html. On current new materialism 
ested in how feminist thinkers, science and technology scholars and contemporary philosophers have been addressing the question of "how does matter matter". This is a question that has gradually grown as part of the post-representational philosophies, feminist epistemologies and for example also some developments of Gilles Deleuze's thought. I myself have been interested in how this can be related to questions of materiality of media. Media theorists such as Friedrich A. Kittler and others have been instrumental in reminding us of the infrastructural and hardware issues that underpin technical media culture. Especially Kittler's role is well acknowledge and documented, the other key thinkers of the past 20-30 years in German-speaking areas less so. This is why we with Geoff WinthropYoung and Anna Tuschling established our new book series Recursions with Amsterdam University Press, to highlight the wider context of material media theory, media archaeology and for example the work on cultural techniques. In the German context and subsequently also internationally, Kittler's take was always executed in provocative ways, addressing the archaeologies of modernity. But one thing that was not so much present was the environmental context similarly as it was absent in a lot of informational and cybernetic accounts, despite their talk of the environment in relation to the system, or circuit. For me, the question was always also about the rather literal environmental questions: how is the earth being mobilized as part of the creation of media technologies, in terms of the materials and the labour involved. This has meant trying to combine issues articulated in new materialism together with some political and historical contexts that are crucial to the materiality of technical media - from gutta-percha used in cable insulation (thanks to the provision from colonised continents) to contemporary rare earths that are essential for so many technological devices. This is the other story that is not contra Kittler, but addresses some of the blind spots. Furthermore, I was always much more interested for example in feminist theory, which is definitely not something that has always been articulated in relation to material media theory from Germany. This does not mean that there have not been great counter-examples. Think of for example Marie-Luise Angerer's work that is now being translated into English as well.

\section{Medianatures}

AR: You describe a double-bind between media and the geophysical which you call the sphere of medianatures. On the one hand, media are enabled through geophysical material. On the other hand, the geophysical may be transferred through media - it is made perceivable through visualisation, sonification or simulation.

When reading your description of the double-bind and medianatures, this differentiation sometimes seemed to suggest a trade-off. While media lead to exploitation of raw-materials in order to bring them into being, they also give

projects, see for example the EU COST project on How Matter Comes to Matter led by Iris van der Tuin with wide representation from a range of European countries: http://www.cost.eu/COST_Actions/isch/Actions/IS1307. 
shape and a voice to earth. Of course, you state that images such as the blue marble are not just the cause of a technologically induced humanism, but are at the same time subjected to corporate and national interests. Within the doublebind which you point out, how do you account for media misrepresentations of ecological concerns? You mentioned for example - and I will come back to this point later on - that one often encounters the misleading promise of disappearing hardware (which is in fact rather hidden and literally buried).

JP: I do not really deal with this level of media representations of climate change for example how media misrepresents ecological concerns. I think that issue runs deeper than just how media addresses or misrepresents issues. It is actually part of the wider context in which the Carbon Combustion Complex (as Naomi Oreskes and Erik Conway coined it) of energy companies, manufacturers, marketers, think-tanks - posing as neutral climate researchers - are linked to certain media companies and their representations. For me, the concept of medianatures is a continuation of Donna Haraway's naturecultures that emphasises the interacting continuities between what we thought were distinct fields: nature and culture. Indeed, the media technological is intensively linked with natural materials and energies (and of course worlds of synthetic chemistry), which is a question of theoretical interest as well as politics of materiality with impact on climate change and environmental issues. It is of course true that we are often catered the idea of hardware as disappearing or perhaps always already immaterial - that the digital does not carry a weight but is the sum of its mathematical transactions in topological dimensions without a topography - but this is just blatantly wrong. Influential accounts such as Mark Weiser's have since the 1980 s and 1990 s spoken of the computer of the 21st century as the multiscreened device but also as ubiquitous, disappearing as part of the environment. But that indeed is a mere backgrounding of the materiality of the computational to the infrastructures in which it takes place. It is not immaterial - even if it disappears from before our eyes.

Besides my book, a bunch of recent research has reminded about the persisting materiality of computations, screen culture and also electronic waste, and I want to mention for example Sean Cubitt's, Jennifer Gabrys's and recently Nicole Starosielski's work on these matters. Starosielski just published a fantastic book The Undersea Network, which addresses the rural and aquatic topographies of the 'backbones' of information - cables (copper, coaxial and fibre).

AR: Since you mention electronic waste: your book needs to be situated in the context of Anthropocene/Anthrobscene debates and presents a radically environmental account of media studies. You emphasise that the new media materialism you describe must be understood in relation to temporality and spatial, geological aspects of media. Your understanding of deep time expands on Siegfried Zielinski's use of the concept, particularly by going beyond its mere temporal use. Deep time - as element of a new materialism - combines geology in terms of the ecological affordances enabling digital media, and temporality as non-human earth times of decay and renewal. Thinking about future research drawing on your geology of media, are these aspects which necessarily need 
to be combined (you emphasise their intersections) or possible research lines which may be likewise followed separately?

JP: Indeed, I want the deep time to be taken rather literally: to look at the earth formations as something that is of strategic interest to manufacturing of media technological moment and future, as well as something that has to radically impact our conceptualisation of media. Through studies of media geography and infrastructures we already know that media is not just here, at the interface. We have demanded to move beyond the screen and to the code and even the hardware. And that, I argue, is of course conditioned by the materialities in which it becomes media - and media, in a way, expands as part of the earth histories of mineralisation, (fossil) energy and more. There is a whole climatology of media that needs to be unearthed, and it is something not only for the nonhuman theoretisation but for the politics of environmental issues in media and humanities. The Anthropocene is one name for this context, but increasingly we have tried to invent alternatives. Capitalocene is one in order to discuss what are the political economic contexts of the impact of human involvement. This is where issues of nature, chemistry, political economy, subjectivity and more meet. It is a true ecological issue in the sense that Félix Guattari addressed three ecologies or we can add, the thousand tiny ecologies that constitute our contemporary moment.

\section{The Invisibility of Hardware}

AR: As I mentioned before, you refer to the latent and misleading promise of disappearance of hardware. Corporations 'hide' the ecological impact of media, e.g. behind outsourced or underground infrastructures enabling current media practices. In this context, you point out that in our current media ecologies also "data need air" (Parikka 2015: 24) and with the concept of medianatures you describe how media 'feed' on natural resources. Would you say that a disregard of materiality is a strategic aspect which is characteristic to contemporary media economies, and moreover aims at the justification of current technological developments?

JP: It could be said to be a strategic aspect as well as part of the logic of commodity fetishism operating still and in new global guises in contemporary digital culture. This was highlighted by Ned Rossiter too: we are still dealing with the "fantastic power of the commodity-form to abstract itself from the experience of labor and life". ${ }^{2}$ This strategic immaterialisation as well as the 'disguise of disappearance' functions on many levels. One encounters it in corporate rhetorics and advertising of the digital and now the ubiquitous computing and the cloud as the new hierarchical way of managing computation. One encounters the fallacy of immateriality in the earlier science fiction that escorted the domestication of new technologies of networking, despite since the mid 1990s some of the

2 cf. http://nedrossiter.org/?p=260. 
more interesting writers such as Neal Stephenson already point out that data is governed by infrastructures that take place. I am thinking here of his short piece "Mother Earth Mother Board" that appeared in Wired. And the disappearance takes place, indeed, in the infrastructural laying of the ubiquitous computing and the 'Internet of Things'. None of these things however can dispense with the (by necessity) material production of the technology itself. Even if technology seems to manifest in immaterial impacts and if it seems to disappear from grasp, it is of course always there, even if dislocated from concrete reach. Hence the emergence of 'data server porn': a cultural theoretical and art interested in the geographies of server farms and other important infrastructural nodes at which data materializes, so to speak. Abstraction goes hand in hand with the material infrastructures and labour that are necessary to sustain it.

AR: You are referring to (early) science fiction, and already when reading your comments on seemingly disappearing hardware, I had to think of Spike Jonze's contemporary science fiction drama "Her" (2013) in which the protagonist Theodore Twombly falls in love with his intelligent computer operating system, represented by a female voice. 'She' later leaves him, together with all other intelligent systems who seem utterly frustrated with life on earth. The movie reverses future visions of technology taking over, into technology becoming weary of humankind. It also presents a vision of a technology which is actually independent of materiality and does not even need humans anymore. In your opinion, what does this idea of dematerialised technology say about current visions of future technology, and our view on materiality and techno-human relations?

JP: My friend Benjamin Bratton has written a lovely piece for the New York Times where he addresses this current enthusiasm for the AI. Bratton writes how much of the imaginary around artificial intelligence is about an anthropocentric projection, which might fail to recognize the more radical possibilities. What if, indeed, AI is not interested in imitating the patterns - social or cognitive - of humans but develops in ways that is not a mirroring of the usual spectrum of emotional responses, including the Terminator-scenario of annihilation of the meat intelligence called the human. My own take was to approach this issue of intelligence and embodiment though the detour of alien intelligence and its media archaeology; in Insect Media I had focused on this question of how do other, non-anthropocentric forms of intelligence and embodiment feature as part of history of technological as well as the techno-scientific imaginary. The insect is one such animal and also a conceptual figure, which was a constant reference point to the non-human world at least since the 19th century (in different ways of course already earlier). Besides the imaginary, the embodied intelligence of e.g. ants became integrated into the new ways in which vision and environmentally coupled intelligence emerged as part of cybernetics. Especially Herbert Simon's idea about the ant's intelligence being the way in which it is coupled to its environment was influential. A lot of robotics learned from this as well and nowadays the persistence off the insectoid in swarm as well as optimisation algorithms tells an informational story of this history of animal worlds and technology. 


\section{Psychogeophysics}

AR: In order to expand and rethink the ways how scholars may look at nonhuman elements in media studies (and beyond), you suggest to look at nonorganic actors. You draw on the term of psychogeophysics as an approach which addresses "thresholds of perception" (Parikka 2015: 61) - since these thresholds have a bearing on limitations of media analyses: on what is often missing or not taken into account.

While geophysics, as natural science discipline concerned with earth's physical features and processes, mainly draws on quantitative methods and the measurement of current/historic developments, psychogeophysics seems to be grounded in qualitative, empirical investigation. You present artistic projects which literally give voice to the nonorganic, such as earthquake sonification and the recording of glacier soundscapes. Articulated and inspired by such artistic practices, you suggest psychogeophysics as ethico-aesthetic perspective which addresses interrelations between the biological, nonorganic and social (ibid.: 67).

First of all, I was wondering what kind of further research you envision here: scholarly analyses which pay attention to artistic projects as early echoes of developments in medianatures, or which make use of such approaches themselves? Second, to what extent does psychogeophysics 'merely' render invisible/ silent processes perceivable, and in how far does and should it involve prognostic or speculative elements and narratives of possible futures? Particularly with regards to your chapter on "future fossils", I was also wondering how your approach relates to concepts such as sociotechnical imaginaries, as collective visions of desirable and possible futures?

JP: Psychogeophysics is one of my favourite concepts in the book. It is not my own invention but I follow some of the earlier discussions like the one articulated in Mute magazine some years ago. Psychogeophysics aims to develop the Situationist focus on psychogeography by underlining the importance of not merely urban but planetary dimensions. As it is poetically defined: "Psychogeophysics; just as the entire weight of the earth conspire to pull down suspended objects (gravity; a relatively weak but keystone force) the human condition is being shaped by the entire earth: psychology as plate tectonics of the mind." One can spot echoes of Robert Smithson's art and writings - the abstract geology of mind. And it speaks to a range of recent years of projects of psychogeography and technological arts.

For me the interest is not merely scholarly. I use a lot of art projects and methods as the focus of the book and as inspiration of how to map contemporary issues of geopolitical aesthetics. But I see that there is a lot that can be done in terms of the art and design projects too. There is a lot that did not make it to the book; for example Liam Young's Unknown Fields Division design studio has engaged with fascinating projects that have to do with the material transforma-

3 cf. http://www.psychogeophysics.org/wiki/doku.php?id=summit:what_is_ psychogeophysics. 
tions that define the contemporary era of technology and materials. ${ }^{4}$ For the Victoria and Albert Museum (London) they prepared the radioactive vases as an odd sort of a design object with multiple chemical, geographical and conceptual legacies built into it. But it was also a story of 'Behind the Scenes of Technology' that travelled shipyards and containers, factories and mineral mines. That's indeed the other story of technology and media we need to address, not just what we encounter as the ready-made devices for entertainment. Recently the studio has been engaging with Lithium Dreams-project that looks at the lithium industry, important for the sustainable green future - but which reveals a rather interesting story relating to infrastructures of planetary scale.

So it is not only the art projects, but speculative design in methods and projects that is of interest in the context of materiality of contemporary computational and technology. Speculative design can work on issues most relevant for contemporary geopolitical condition. This is also psychogeophysical mapping. It's not merely about making things visible, although there is a longer legacy of "Making Things Public" that has defined the interface of STS, art methods and design; the Bruno Latour and Peter Weibel exhibition and book has inaugurated a lot of interesting things, but also in such projects it is not merely a simple "visualization" that is at question. ${ }^{5}$ We have to account for the actual media, the interface, what enables things to become visible as the production of such things. Hence, also speculative elements and speculative design is important way to intervene in the contemporary production of geopolitics and material infrastructures. Take also Donna Haraway's interest in string games (like cat's cradle) and how she continues this idea: "String figures are SF games. SF games are science fiction, science fact, speculative fabulation, speculative feminism, soin de ficelle, so far." (2015: 257)

You are perceptively pointing to how themes such as the chapter on fossils is about the temporal imaginaries that define key traits of the 19th century as well as our 21st century: the imaginary of the post-human planetary, of extinction and of future waste that is a horizon of a speculative future we have to respond to now. My media theoretical argument is one among many recent accounts which also include such as Naomi Oreskes and Erik Conway's The Collapse of Western Civilization, a little book about the future-now, a future imagined; a geopolitics of fossil fuel industries and their wider political links, role of science and the speculative geopolitics of near future after risen water levels. I engage with some issues that are specifically about media waste but it also is about this sort of a temporal level. Temporality is anyway the key sub current of A Geology of Media. We need multiple, complex and innovative concepts of time that are worthy of our times.

4 cf. http://www.unknownfieldsdivision.com/summer2014china-aworldadriftpart 02.html\#7.

5 cf. http://www.bruno-latour.fr/node/333. 


\section{Methods and Approaches}

AR: I found it quite interesting how you describe and combine different scales of media analyses. While you zoom in on the media components, you zoom out when it comes to the dynamics, economics and politics in which these raw materials are embedded in before becoming media. This seems, for example, decisive for your study on the role of dust in contemporary media ecologies, which you present in chapter 3 , but also with regards to the critical media art which you present throughout the book.

JP: To continue on what I said earlier about time and temporality: To be interested in multiple scales on which reality is being constantly built, co-constructed, is not a luxury but a necessity for critical theory nowadays. A lot of theory feminist theory realised this early on, similarly some STS. We need to abandon such worn out scales of reference that do not address the currently crucial questions and engage with what are the microscopic - or then planetary level - processes that define issues such as the social. This does not necessarily mean abandoning the important legacy of critical thought for example in feminism and post-colonial theory, but to build an understanding how such issues are to be addressed in our current situation. The same ideas need to apply to how we think of media. We have grown to appreciate a range of techniques, technologies and processes as pertinent to media analysis. To echo W. J.T. Mitchell's argument about visual culture studies: we cannot take vision for granted, but part of the analysis is to problematize it and historicise it. Same thing with media analysis: what is mediation, where do we focus when discussing media culture and technology? What is the scale and object of reference?

A range of approaches in Germany have made headway in this field of questions and pushing media studies forward. Most recently, Bernhard Siegert put it like this:

"Literature and media analysis replaced the emphasis on authors or styles with a sustained attention to inconspicuous technologies of knowledge (e.g., index cards, writing tools and typewriters), discourse operators (e.g., quotation marks), pedagogical media (e.g., blackboards), unclassifiable media such as phonographs or stamps, instruments like the piano, and disciplining techniques (e.g., language acquisition and alphabetization)." (2015: 2)

Media is not merely about mediation but involves issues of technologies of knowledge, as well as for example recently, the infrastructures in which media become understood as objects. It's in the intermedia components that one finds a subliminal 'under the hood' history of media that is not merely of media as the object but as an assemblage of different technologies and techniques. The externalization of what might be mistaken as internal tech-histories of a media is important because it makes us realize the importance of such details, microlevels, for the construction of reality. Indeed, the interest in microtemporalities from Mark Hansen to Wolfgang Ernst corresponds to the shift in conceptual 
focus that is also a shift in methodological focus. And similarly the scales of the Anthropocene are ones that involve a reorientation of humanities methodologies away from methodological nationalism and a reductive focus on humans only, as Rosi Braidotti has demanded.

AR: When reading "A Geology of Media", there were several passages which reminded me of the hacker ethics and where you explicitly refer to hacking culture; particularly I kept thinking of Levi's definition: "Hackers believe that essential lessons can be learned about the systems - about the world - from taking things apart, seeing how they work, and using this knowledge to create new and even more interesting things". ${ }^{6}$ You are of course referring to Kittler whose work was inspired by similar assumptions and to practices such as circuit bending. However, you also propose to analyse "media before they become media" (Parikka 2015: 5) and to radicalise the idea of media studies as 'study of components', down to the level of chemicals, metals and minerals. To what extent would you say is the approach of a hacker similar to the one of a 'media geologist', and how does your approach go beyond the idea of hacking?

JP: The political legacy of the hacker has travelled many routes over the past years with people on the left finding it as inspiring as the business school/ creative industries and neoliberal thought leaders too. The hacker became over the past decades the mythological ideal type of the digital era. It always carried a lot of interesting things when it comes to techniques combined with an interest of knowledge: what does it mean to produce critical insights by doing? What is practice as a form of knowledge? How does opening up a device trigger massive amount of questions that move from conceptual to political economic situations? What are the sites, geographies of hackers? These follow the genealogy of the hacker, but I indeed became also interested in the oxymoronic expression of a media geologist, or "pseudo-geologist" as I don't claim to work in the field of geology. It means an awareness of not merely hacking the devices, but to engage in the wider issues in which devices come to being: material production and mining, refining rare earths and the toxic residue next to the refinement centres which define a different sort of geography of the digital. Call it the underbelly of the digital: places like Baotou in Mongolia where mined ores are cleaned and acidified for the rare earth elements necessary for digital globalisation. Now it is characterised by the toxic sludge lake, the residual of the purification. It's also never just the digital - Baoutou has had the facility since 1958.

In art practices, one key inspiration for the whole book was the Jonathan Kemp, Martin Howse and Ryan Jordan collaboration on the Crystal World where they pushed hacker practices towards metallurgy, chemistry and opening the hardware down to its constituent elements. This is where the politics of hacking broadens even outside questions of software and hardware: the methodologies of opening up, exposing and rewiring become applied to things like the logistics and the material conditions of such devices and their algorithmic existence.

6 See http://www.gutenberg.org/ebooks/729. 


\section{Media, Art \& the Humanities}

AR: Chapter 2 and 3 of your book present an at a first glance unlikely combination of case studies: mining and contemporary art. Already with regards to your media archaeological research you are well known for emphasising the close connection between media theory, aesthetics, and art. In "A Geology of Media" you likewise stress that art is not just an illustrative element of your research, but that it shows and sometimes even precedes your theoretical insights. I found this a striking combination: on the one hand you draw heavily on the natural sciences - e.g. with concepts such as chemistry, archaeology, and of course geology - while likewise giving weight to artistic practices and projects. Why are such arguments, related to the ecological aspects of media, visible in art first? At the same time, what motivates you to draw on natural sciences disciplines and concepts, and to use them as core ideas of your media theoretical work?

JP: Books can be written in various ways. They take alternative paths based on your own decisions but also because of the wider environment in which they are written. I learned over the years a lot from people like Sean Cubitt - who has a fantastic new book manuscript ready on the eco-political aesthetics with a strong political economic bent. I decided that I want to emphasise my own take slightly differently but as a parallel stream, that engages with the idea of art methods as probeheads for an alternative media materialism. I am anyway interested in the questions where aesthetics meets technology, and the other way round: how history of technology is the history of perception and sensation; of regulation and production of the ways in which bodies conduct. Media is about the processes of drill and practice in which we learn sensation.

The natural sciences are part of the mix. A media archaeological methodology is anyway about the back and forth movement between art, science and media that are not read only internally in their own contexts. A Geology of Media is not a straightforward media archaeological study but it also demonstrates this necessity to work with eclectic source basis. It's how our modern world is built anyway. It also has implications how we think about the humanities and how we expand the work of humanities.

AR: Before discussing implications for the humanities, I would like to address the relevance of your book for research on digital media specifically. "[W]e need to steer clear of the "psychopathia medialis'" (Parikka 2015: 43) - this is what you recommend to media scholars and you emphasise that "a lot of science happens way before discursive wizardry of creative technology discourse” (ibid.: 36 ). Both statements imply that many media scholars somehow tend to focus on a certain side of media and neglect even more important aspects and hence alternative perspectives. So, your criticism seems to be: researchers in digital media/technology studies often look at the wrong things - media as they are presented as products, as what we are supposed to see them - and they look for them in the wrong places. 
JP: Instead of pointing the finger and saying what is the wrong way, I want to provide alternative accounts in my own work. It's not about saying "don't do it like this" but showing that it can be done "like this" too. The way in which media studies has been conducted has responded to important issues from gender to political economy, class to the technological constitution of society. But I want to look at what's been left out and what are the areas we might need to develop conceptually and methodologically. It's indeed the case that media should not be approached merely as what is packaged for us as media. Then we would be only the marketing arm of the consumer product industry. Media studies and the humanities need to be much more and produce their own strong stake in the world.

I do not want to give a guideline what and how others should do things, but my books suggest ideas: environmental issues in connection with a celebration of conceptual themes; of theory that is a necessity for academia, not just a thing to be tolerated by management teams of corporate universities. My own interest in themes of the posthuman, non-human and new materialist cultural theory are ones that acknowledge also the genealogies of theory: feminist theory, poststructuralism and more. In a recent interview, Donna Haraway said something similar: we need to cite, not to glorify any imaginary originality but to think in collectives that are contemporary and historical. It is "the question of how to live with our inheritances, how not to disown them. We have many inheritances, so we need that kind of humility, the humility of never starting from scratch and never starting clean, as well as inheriting obligations we did not and cannot choose, but which we must respond to." (Haraway 2015: 261) Those are really strong words.

AR: Your book indeed reads like a manifesto for an interdisciplinary branch of media studies which recognises its own social and ecological responsibility. So, apart from understanding what it practically means to choose a geology of media as research approach, I was wondering about the implications when choosing this kind of approach: what kind of social responsibility do researchers in this field assume? What are the ethical, and inherently ecological implications of media geology?

JP: Media geology continues the design brief, given by Rosi Braidotti in her The Posthuman-book, to look beyond anthropocentric accounts. In this sense, I try to execute a geocentric archaeology of media that looks at conditions of existence of media technologies in the planetary. This reaches out to themes in philosophy and design, contemporary art and technology. It is already this trespassing of disciplinary boundaries that speaks to the question of what sort of ethics are needed: ethics that produces more than just an apocalyptic sentiment. It is an ethics that does not centre on the human - or its non-existence - as the only axis that is of significance. Instead, a proper ethics moves on multiple ecological scales. 
AR: On a broader scale, throughout the book, you refer to the role of the humanities. Already in the preface you state: "our continuous trespassing over the boundaries of sciences and humanities cannot be neglected by closing our eyes and thinking of semiotics" (Parikka 2015: viii). You propose that "we need to resist the old-fashioned methodological dualism haunting disciplinary thinking of the past" (ibid.: 20). I would like to conclude this interview with regards to a question which you raised yourself: "Indeed, such aesthetic questions are in prime positions to raise the substantial ethical question for humanities: can we remain just-humanities in an age of planetary scale engineering and massive changes to the very physical ground in which we live?" (ibid.: 69)

Developments and labels such as "digital humanities" or "engaged humanities" seem symptomatic for the high pressure under which humanities currently 'justify' their relevance. What kind of humanities do we need when aiming at an acknowledgement of the challenges of the Anthropocene/Anthrobscene?

JP: It is a big and important question! The new humanities have quite the task as it means being aware of key archaeologies and genealogies of science and technology that define what the human is in contemporary technological society. The determinations of the human are not merely in those areas that were identified by the humanities traditionally. Hence there is a necessity to think in between and across disciplines and faculty lines. That is part of the ethics mentioned above too.

Is Digital Humanities one answer? Yes, if it is able to develop itself as Cultural Criticism, like Alan Liu recently flagged. But it indeed has to embrace also the wider function as critique with important social and cultural functions, and not merely as a toolbox of instrumental means that instead of challenging, might consolidate the existence of the stable division between quantitative and qualitative methods that present themselves as neutral.

I really like how Braidotti is approaching these things: reminding that the old humanities were not necessarily always the thing we should be saving anyway. Much of it was branded by Eurocentric projects with difficult attitudes towards women and 'other Others'; feminism and post-colonial theory had to work hard to change Humanities over the decades. Now the question is how to build on this legacy and to cherish the work done also in animal studies and many other fields that understand the ecological imperative: any question of the Humanities is a question of its web of interdependencies: animals, technology, various environmental issues, etc. Again, this perspective involves the ethics of multiple scales. We need to be able to articulate the necessity of this for academia and also the necessity of theory and such cross-disciplinary methodologies like media archaeology. Anthropocene is one name for the recent impulse to think anew the scales - the zoom in/zoom out work that one finds as one methodology of conceptual scale. But so are its companion concepts, Capitalocene, Cthulhucene (Haraway) and why not, also the Anthrobscene - the obscenity of the systematised death cult of corporate planetary capitalism. Haraway has it right: it's not merely about the species of Humans and their impact but the 
specific exploitative politics and economy of the past hundreds of years that have produced this situation.

I am currently starting with two colleagues, Lori Emerson and Darren Wershler, a new project on "labs", laboratories in the humanities. We are interested in how these sites - both as actual spaces and as symbolic terms for activity - are used to refer to inter- or transdisciplinary practices. It's not a story of mere celebration of the lab as the new necessary trend for the humanities, but also a critical look at how there is the constant risk of such practices being hijacked as part of the corporate university that cherishes the project, the temporary, the precarious innovation. Labs are anyway to me an interesting way of approaching what are the sites of theory: the settings, spaces and institutions in which academic theory, concepts and new methodologies are happening also sometimes in collaboration with creative practice such as with designers or artists.

\section{References}

Braidotti, Rosi (2012): The Posthuman, Cambridge: Polity.

Bratton, Benjamin (2015): “Outing A. I.: Beyond the Turing Test.” New York Times, Feb 23, 2015 (http://opinionator.blogs.nytimes.com/2015/o2/23/outing-a-i-be yond-the-turing-test).

Cubitt, Sean (2011): "Current Screens." In: Oliver Grau (ed.), Imagery in the 21st Century, Cambridge, MA: MIT Press, pp. 21-35.

Ernst, Wolfgang (2013): “From Media History to Zeitkritik." In: Theory, Culture \& Society 30 (6), pp. 132-146.

Gabrys, Jennifer (2011): Digital Rubbish: A Natural History of Electronics, Ann Arbor: University of Michigan Press.

Guattari, Felix (2000): The Three Ecologies (translated by Ian Pindar/Paul Sutton), London: Athlone Press.

Hansen, Mark (2014): Feed Forward: On the Future of the Twenty-First Century Media, Chicago: University of Chicago Press.

Haraway, Donna (2015): "Anthropocene, Capitalocene, Chthulhucene. Donna Haraway in conversation with Martha Kenney." In: Heather Davis/Etienne Turpin (eds.), Art in the Anthropocene, London: Open Humanities Press.

Kittler, Friedrich A. (1990): Discourse Networks 1800/1900 (translated by Michael Metteer with Chris Cullens), Stanford, California: Stanford University Press.

Latour, Bruno/Weibel, Peter (2005, eds.): Making Things Public, Cambridge, MA: MIT Press.

Liu, Alan (2012): "Where Is Cultural Criticism in the Digital Humanities?" In: Matthew K. Gold (ed.), Debates in the Digital Humanities, Minneapolis/ London: University of Minnesota Press, pp. 490-509.

Mitchell, William J.T. (2010): “There Are No Visual Media.” In: Oliver Grau (ed.), Media Art Histories, Cambridge, MA: MIT Press, pp. 395-406.

Oreskes , Naomi/Conway, Erik (2014): The Collapse of the Western Civilization. A View from the Future, New York: Columbia University Press. 
Parikka, Jussi (2015): A Geology of Media, Minneapolis/London: University of Minnesota Press.

Rossiter, Ned (2011): "Logistics, Labour, and New Regimes of Knowledge Production" (http://nedrossiter.org/?p=260).

Siegert, Bernhard (2015): Cultural Techniques: Grids, Filters, Doors, and Other Articulations of the Real, Vol. 22, New York: Fordham University Press.

Simon, Herbert (1969): The Sciences of the Artificial, Cambridge, MA: MIT Press.

Starosielski, Nicole (2015): The Undersea Network. Durham, London: Duke University Press.

Stephenson, Neil (1996): "Mother Earth Mother Board" (http://archive.wired. com/wired/archive/4.12/ffglass_pr.html).

Weiser, Mark (1991): “The Computer for the 21st Century.” In: Scientific American 265(3), pp. 94-104.

Zielinski, Siegfried (2006): Deep Time of the Media (translated by Gloria Custance), Cambridge, MA: The MIT Press. 